Journal of Design and Science • Issue 6: Unreal

\title{
QAnon and the Emergence of the Unreal
}

\section{Ethan Zuckerman}

Published on: Jul 15, 2019

Updated on: Jul 26, 2019

DOI: 10.21428/7808da6b.6b8a82b9 
The Grass Valley Charter School in northern California teaches 500 students from kindergarten to eighth grade using principles from Outward Bound and other "active learning" methods. Recently the school has been in the news not because of its pedagogy, but due to the effects of an unusual eruption of unreality.

On May 11, 2019, the school was scheduled to hold its Blue Marble Jubilee annual fundraiser. In the weeks leading up the event, however, school administrators began receiving calls informing them that a "credible source" had issued warnings that the fundraiser would be a target for an unspecified attack. The people calling the school made clear they weren't threatening an attack-they were warning the school about events they anticipated after deciphering a tweet from former FBI director James Comey. 
urge the school to call off the event, lest someone show up to "protect the school" and cause mayhem. That fear was not entirely unwarranted - in December of 2016, a conspiracy theorist showed up at a Washington, DC pizza parlor to "self-investigate" a conspiracy theory spread online, and discharged a semi-automatic rifle in the restaurant before being arrested.

It is perhaps too easy to dismiss QAnon as the craziest manifestation of a crazy time in history, when global narratives about the spread of liberal democracy are rapidly reversing, authoritarian nationalism is re-emerging, and every established political norm seems negotiable. By embracing the most bloody and absurd theories with a credulity that's more easily parodied than examined, QAnon makes it hard for us to take them seriously. But it's a mistake to look at the Grass Valley Charter School episode and shrug.

In 2018, Time magazine declared " $Q$ " one of the 25 most influential people on the Internet, alongside more recognizable figures like Donald Trump, Kanye West and Matthew Drudge. It's a reasonable argument to make. Q's "drops" - thousands of cryptic posts posted on image boards 4chan and 8chanhave led to countless YouTube videos, podcasts, and an explosion of online and offline writing trying to interpret the utterances of the anonymous "Q Clearance Patriot." In March of 2019, QAnon: An Invitation to a Great Awakening, a book written by QAnon followers and supporters, peaked at \#2 on Amazon's list of best selling books.

QAnon is interesting not because its predictions of political revolution are correct-they are not. And while some believers in QAnon have been linked to violence - in particular, the former US Marine who held a one-man standoff at the Hoover Dam, armed with an AR-15 rifle, and who referred explicitly to the QAnon conspiracy-threats of violence are not the main reason to pay attention to this community. Instead, QAnon is important because it is a harbinger of things to come.

A movement like QAnon is an inevitable outgrowth of the Unreal, an approach to politics that forsakes interpretation of a common set of facts in favor of creating closed universes of mutually reinforcing facts and interpretations. Whether the QAnon community flourishes as Donald Trump seeks their approval in his quest for a second term or sputters out as their predictions grow ever more fantastical, the dynamics that make QAnon possible are the same dynamics that are reshaping our politics more broadly.

\section{How is this conspiracy theory different from other conspiracy theories?}

QAnon is a big tent conspiracy theory, a meta narrative that knits together contemporary politics and hoary racist tropes with centuries of history behind them. At its core is the idea that all American 
presidents between John F. Kennedy and Donald Trump have been working with a cabal of globalist elites called "The Cabal" to undermine American democracy and forward their own nefarious agenda. (Predictably, the cabal includes investor/philanthropist George Soros and the Rothschild family, but the theory is more anti-elite than explicitly anti-Semitic.) In all versions of the mythos, the Cabal seeks to destroy American freedom and subjugate the nation to the wills of a world government. In some versions of the mythos, the agenda also includes pedophilia, blood sacrifice, Satanism and other attention-getting transgressions.

Ultimately, QAnon is a hopeful conspiracy theory. "The Storm” is coming. Donald Trump is secretly working in league with Robert Mueller to arrest Hillary Clinton, Barack Obama, and other members of the Deep State who are working to destroy our nation. Sealed indictments have already been filed, and arrests-followed by military trials, and possibly executions - are coming any day now.

In many ways, QAnon behaves the way most conspiracy theories do. Its core appeal is its sense of a master narrative, an explanation for otherwise disturbing and confusing events that assures believers that they understand the big picture in ways non-believers do not. This master narrative gives believers a sense of control over uncontrollable events. QAnon followers continually remind each other to "trust the plan," that Trump and his team have reasons for the steps they are taking, including their decision to reveal their plans only through the Internet's shadiest message boards. 
theory, like the end of the Mueller investigation, are turned into evidence that those behind the conspiracy-Trump and his allies, including the author of the $Q$ drops-are clever beyond our understanding.

Cass Sunstein understands conspiracies as the product of "crippled epistemologies," which accept only a limited set of sources as authoritative. Here, Donald Trump's relentless attacks on the mainstream media have helped constrain the range of sources QAnon supporters are willing to believe, dismissing virtually any conventional journalistic authorities as part of the globalist elite responsible for all societal ills. The authoritative voices in QAnon are those most dedicated to understanding Q's missives.

But QAnon departs from the pattern of conventional conspiracy theories in some novel ways. Traditionally, the audience for conspiracy theories are those who feel marginalized from ordinary politics and are disengaged. Now the most prominent conspiracy proponent is, arguably, the world's most powerful person. Donald Trump returned to political prominence in 2010, promoting the "birther" conspiracy theory speculating that Barack Obama was not a US citizen. Trump surfaced the idea of running for president in 2011, referring specifically to his belief that Obama's presidency was illegitimate due to his citizenship. Since taking office he has relentlessly attacked mainstream media, which is a core actor in QAnon's unreality, and his voluble conflicts with government agencies like the FBI gives apparent support to the idea that he is at war with a "deep state" determined to unseat him.

Furthermore, Trump frequently amplifies conspiracy theorists, including prominent QAnon believers, especially through his Twitter feed. A generous reading of this behavior is that Trump is amplifying anyone who vocally supports his policies, some of whom happen to be conspiracy theorists. Another interpretation, offered by Dr. Joseph Uscinski, is that Trump saw conspiracy theorists as an "underserved market" during the primaries for the 2016 election and that Trump continues "dancing with the one who brought him to the prom." More disturbing is the possibility that Trump genuinely sees himself as a victim of forces beyond his control and the chief actor in a battle for the soul and future of a nation. Whether Donald Trump is a conspiracy theorist or a skilled manipulator of conspiracy theorists, the peculiar logic of "deep state" narratives is a shaping influence on his presidency.

\section{The radically participatory conspiracy}

Trump's apparent alignment with some of QAnon's ideas isn't the only distinguishing feature of this conspiracy. QAnon may be the first conspiracy to have fully embraced the participatory nature of the contemporary internet. 
The core texts of the QAnon movement are a set of more than 3,000 brief messages posted on Internet message boards 4chan and $8 \mathrm{chan}$. These message boards are anonymous, chaotic and ephemeral, all characteristics that would seem to mitigate against the broad transmission of these missives. Why would "Q Clearance Patriot" (the person or persons who claim proximity to Trump and who have detailed understanding of the conspiracy) share valuable insights in such an unlikely venue? Anonymity, of course, as well as a belief that the open-minded denizens of those fora would be readers capable of assembling the "crumbs" dropped by Q. (Q:\#6)

The other reason, of course, is that the process of deciphering and interpreting these vague clues is a hell of a lot more interesting than reading the rantings of a paranoid mind. Author Walter Kirn identifies $\mathrm{Q}$ as a storyteller who has mastered a fundamental truth of narrative on the internet: "The audience for internet narratives doesn't want to read, it wants to write. It doesn't want answers provided, it wants to search for them." Members of the QAnon aren't just readers of Q's "drops" - they are the "bakers," assembling crumbs into coherent narratives and predictions. And while assembling and re-baking crumbs is unlikely to yield anything culinarily appealing, participation in constructing the $Q$ narrative is clearly a fascinating pursuit for thousands of co-creators.

Q's literary style is one of relentless questioning, demanding that readers fill in the blanks left in the narrative:

\section{Where is Huma? Follow Huma.}

This has nothing to do w/ Russia (yet).

Why does Potus surround himself $w /$ generals?

What is military intelligence?

Why go around the 3 letter agencies? (Q:\#2)

The "baking" of Q's crumbs has led to a complex ecosystem that almost resembles Talmudic commentary, with some "researchers" competing to interpret Q's pronouncements and tie them to breaking events in the news. Other researchers are numerologists, linking the "tripcodes" used in Q' $\underline{\mathbf{s}}$ posts (tripcodes are a weak form of cryptographic signature designed to allow anonymous posters to link authorship of multiple posts) to thousands of books indexed by Google Books. Q's devotees are incredibly prolific. The leading $Q$ podcasts have published thousands of episodes, and the thousands of videos explaining QAnon routinely register hundreds of thousands of views on YouTube.

Most commentary on the QAnon phenomenon is so quick to denounce the absurdity of the community's obsessions that it fails to consider what's interesting and novel about the movement. A laudable exception are the three authors behind QAnon Anonymous, a Patreon-supported podcast that 
"chops \& screws the best conspiracy theories of the post-truth era." QAnon Anonymous suggests we understand QAnon as fan fiction: "QAnon has a canon, but the canon is basically this coded language of the drops. The tapestry of the story is done by these amateur researchers...it's decentralized storytelling, like thousands of different fanfic threads going on at once with very little to chew on at the center." While we might think this lack of a strong canon would present an obstacle to the strength of QAnon, it actually serves as a strength.

Much as there's a robust online community extending the narrative of virtually any TV show, movie or beloved work of fiction, QAnon's bakers are taking the narrative sketches offered by $\mathrm{Q}$ and extending them into a rich and detailed fantasy world. While there's ample fan fiction about well-loved stories like the Harry Potter series or Star Trek, many fanfic aficionados choose to extend flawed texts, fixing their shortcomings and amplifying their strengths. It's far more fun to write fanfic for a bad show than for a perfect one, and the narrative put forward by $Q$ on 4Chan and 8Chan is deeply flawed. It is filled with events that haven't transpired and predictions gone wrong. What is perhaps most remarkable about QAnon is how resilient it has been to obvious setbacks, including the inconvenient truth that neither Hillary Clinton nor Barack Obama have been arrested.

The QAnon Anonymous team considers QAnon to be "an improvisational game" where the players compete, "looking for an interpretation that will go viral within the QAnon community." As a result, QAnon bakers are not only co-authors of the narrative, they're proselytisers, both for the broader conspiracy and their particular interpretive frame. We see the same dynamics in antivax, another conspiracy that's having a moment in the sun with the return of measles outbreaks in the US. It is insufficient to be persuaded by the antivax or QAnon movements-those who've joined the movement feel an obligation to share the truth with those whove yet to be enlightened. Those who are most successful in converting others are rewarded with attention, a commodity that is easily convertible into other currencies. Most of the popular QAnon podcasts feature sponsored advertising, notably products like emergency flashlights designed to help listeners survive the social upheavals destined to come about during The Storm. (There is, of course, the inevitable backlash to the commercialization of QAnon, with disaffected movement participants complaining that the conspiracy has been hijacked and is now being exploited for financial gains.)

\section{Participatory media and the new normal}

The participatory advocacy that QAnons are engaged in is a phenomenon that's $\underline{\text { grown increasingly }}$ common as news media and participatory social media have become inextricably intertwined. In the broadcast model of media, the events of the world were interpreted by a group of professionals who selected a subset of possible narratives to amplify, then delivered them to audiences who had extremely limited channels in which to offer feedback and input. That model has been largely replaced 
by one in which the audience is a full participant, an essential circulator of information by retweeting, sharing and remixing it. The new centers of power in this ecosystem are discovery engines like Google and Facebook, which rely on feedback from users to determine what stories to feature or ignore. Additionally, the people formerly known as the audience are now creators of content, adding new chapters to existing stories, and telling entirely new stories.

The field of Civic Media understands participation in this process as a key form of civic participation. Much of this participation is laudable, and a positive development for making marginalized issues more visible. The use of participatory civic media was how reports of sexual harassment in Hollywood turned into the \#metoo movement, with tens of thousands of women joining Alyssa Milano in portraying the sheer volume of women who had personally been harassed or abused. In the Black Lives Matter movement, participatory media was critical in documenting police violence against protesters, in demanding attention to protests and the reasons behind them, and in framing the issue of police violence against people of color as narrative of civil rights violation that links together individual acts of violence. The emergence of spaces where non-professional individuals can report what's happening in their communities, amplify stories that might have otherwise been missed, and demand attention towards subaltern narratives is, in the main, an enormously positive development for open societies.

But much as QAnon is an understandable consequence of a president who gives credence to conspiracy theories, QAnon is also a predictable outcome of the rise of this new form of participatory civics. The same tools that allow the emergence of narratives that have been subjugated due to racism, sexism and classism allow the emergence of narratives that were previously ignored because they have little overlap with consensus reality.

With revelations about the use of Facebook groups by the Russian Internet Research Agency to create conflicts between groups of Americans and force cleavages within left-wing movements, it's clear that the social media/news loop is being manipulated. What may be more relevant is the fact that these systems are also useful to those acting "in good faith"-i.e., not misrepresenting their identities or intentions - towards horrific ends. The man who killed 50 Muslims at prayer in New Zealand was not fooled by a Russian plot. Instead, he was recruited by online extremists who believe a conspiracy in which Catholics are being intentionally displaced by Muslims in order to destroy aspects of European culture, a narrative not far from the core QAnon mythos.

Because the Internet is for QAnon and extremists as much as it is for \#metoo and Black Lives Matter, the conversation spaces around conspiracies are hard to distinguish at a glance from other forms of newsmaking that happen today. Q comments on the events of the day, linking to YouTube videos and threads on Twitter, and a devoted community interprets and spins his/their commentary in a way 
that's similar to the President of the United States commenting and linking on Twitter, with an army of journalists reacting to his every tweet.

This media landscape is the new normal. Its key characteristic is not mis-, dis- or malinformation. Instead, the key feature is that every assertion has a point of view behind it and is supporting someone's agenda above other possible agendas. Each story reported or ignored, each fact marshaled or forgotten is weaponized. In such a world, Donald Trump's complaint that the media fails to report on the successes of his presidency is not merely whinging. It is the reason why the media is his most potent antagonist and the "enemy of the people," because the reality they report is in direct conflict with the one he is selling. The conflict between Trump's reality and that of the mainstream media leads to the sense that we are no longer arguing a partisan battle over the interpretation of a common set of facts, but over facts from our own realities that both represent and lead inexorably to our own point of view.

I have started to think of this clash of realities as "the Unreal." I don't mean to identify a singular unreality-Trump's, QAnon's, or anyone else's - but to make the point that what's real to you is unreal to someone else. Like conspiracy theories, this is not a new phenomenon. Questions of whether we can share a common reality or whether we will be forever separated by our perceptions and interpretations are the subject of timeless debates in epistemology and phenomenology. What's different now is that these debates have escaped the philosophy classroom and are now infecting every news story and online discussion. 


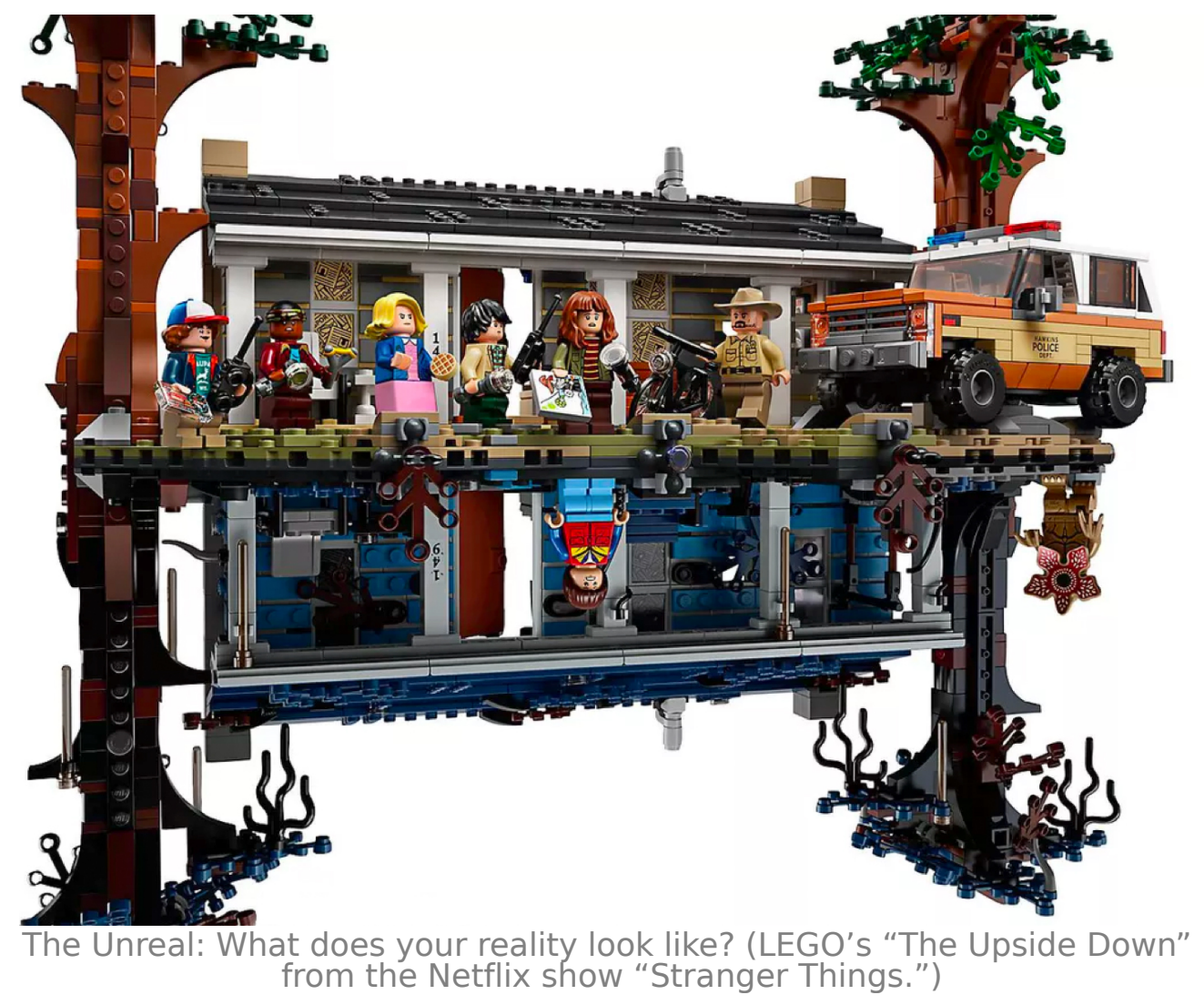

Throughout QAnon is the idea of discovering that our consensus reality is fraudulent, that a darker but truer reality lurks beneath the surface for those brave enough to look for it. QAnons talk about "red pills" and "blue pills," adopting the terms from everyone's favorite mashup of Keanu Reeves and Plato's Cave, the 1999 film The Matrix. In the film, Reeves's character is offered a red pill, which will reveal to him the true and horrifying nature of reality, or a blue pill, which will allow him to remain in happy delusion. For QAnons who've taken the red pill, the world of MSM is unreal, designed to deceive and prevent us from seeing the truth. For those who don't take the pill, those in QAnon are simply delusional, incapable of being reached, and residing in an unreality we have no way of influencing or affecting. 
(The adoption of the term "redpill" precedes the QAnon movement and reflects an even darker unreality. The term surfaced in the "pickup artist" community, which is an online group of men who believe women want to be subjugated to men and will reward abusive and dominant men who manipulate them in certain ways. For them, redpilling means releasing yourself from the notions of gender equality and feminism and accepting their deeply misogynistic worldview. That QAnon adopted this language is not coincidental-both communities evolved within the dank, fetid swamps of 4chan and 8chan, and there is a non-zero overlap behind the "traditional values" preached by some QAnon patriots and the revanchist anti-feminists of the pickup artist scene.)

\section{Who benefits from the Unreal?}

If Unreality is an emergent feature in today's world, it is worth asking questions about its effects. Who wins and loses in a world of conflicting realities? Some implications are obvious. Political consensus becomes more elusive, because finding a common solution requires accepting a common-or at least compatible-analysis of the situation. Reporting the news is increasingly complicated, as reporters trained to act as neutral conduits are obliged to advocate for their perspective above competing perspectives, a process that may further erode already diminished trust in journalism.

But deeper effects, like who the unreal helps and harms or what sustained exposure to unreality does to us as citizens or as humans, is harder to divine.

Propaganda is a form of unreality-an instrumental unreality created by a state rather than an organically grown unreality, as QAnon appears to be - and we can learn something about the effects of unreality from the history of propaganda. Hannah Arendt argued that one of the goals of totalitarian propaganda was to force us to believe in the manifestly untrue. In declaring our belief in something that we knew not to be true, we showed our allegiance to the leader who put it forward. When the leader would change their mind and alter the reality that we shared, it would be spun as necessary for disinformation purposes. The leader understood why we needed to lie at some moments and reveal the truth in other moments, and in showing our willingness to adopt this reality, we showed ourselves giving up our agency, becoming the equivalent of a dog waiting for a command from his master rather than thinking on his own.

But it is not clear that our contemporary unrealities have been weaponized and directed in the instrumental way in which totalitarian leaders used propaganda in World War II. Our world is characterized by a diversity of communication channels, a choice of different (un)realities, rather than the control of communications sought by dictatorships. A plurality of unreality does not persuade the listener of one set of facts or another, but encourages the listener to doubt everything. 
Some actors seem especially comfortable operating in this environment. RT, the Russian state broadcaster, launched its coverage in the United States with a documentary promoting the conspiracy theory that the terror attacks of $9 / 11$ had been an inside job. This theory, not an especially widespread one in the United States, seems an odd way to introduce oneself to a new audience. But RT's slogan, "Question More," reveals the logic behind it. The goal was not to persuade American viewers of a specific conspiracy theory, but instead to persuade viewers that they should question any narrative that they had previously encountered.

A world in which we are constantly questioning is a world that demands endless effort to navigate. It becomes exhausting to follow the news, to understand political developments, to navigate whether a set of facts is believable or is a manifestation of someone's agenda. A logical response to this rise in unreality is to tune out and sit instead on the sidelines. Another response is to cede agency to those who thrive in this climate of unreality, leaders like Putin and Trump, who seem perfectly adapted to this space.

The main byproduct of unreality is doubt, and doubt is dangerous. Doubt makes it difficult to organize - to demand a change-because movements for change require a set of people to agree on a problem and a possible solution. We know from Naomi Oreskes and Erik Conway in Merchants of Doubt that the strategies employed by tobacco companies about the harms of their product or oil companies about anthropogenic climate change were not designed to sway audiences to the corporate narrative, but to generate sufficient doubt to paralyze effective action. As long as there is doubt it is difficult to reach consensus and to move forward. The merchants of doubt wield their product like a weapon, and the primary product of unreality is perpetual paralysis.

We have a tendency to assume, especially in academic communities, that the acceptance of unrealities, whether they are those of vaccine skeptics or climate change deniers, are the consequence of poor education or emergent technologies. Robert Proctor and Iain Boal coined the term "agnotology" to refer to the study of culturally induced ignorance or doubt in order to distinguish ignorance that is consciously created from that which occurs naturally. (I am grateful to danah boyd for introducing me to Proctor's book with Londa Schiebinger on the topic, which introduced me to the term.) Those who benefit from the stasis caused by imposed doubt are those who are already in positions of power. Those who suffer the most are those who have been excluded from power. In that sense, unreality and the doubt it generates is an inherently conservative force.

What's worse, perhaps, is that many of our responses to the doubt brought about by emergent unreality have been reactionary. In much of the discussion of mis- and disinformation is the thinly disguised desire to return to a world where there's a single authoritative voice, a Walter Cronkite to tell us "That's the way it is." There is an understandable temptation to hand more power over control of speech to platforms like Facebook in the hopes that they'll somehow return us to a mutually shared 
reality. This is an unlikely scenario given their role in allowing these splits to emerge. The alternative, asking governments to regulate and control speech in online spaces, seems equally unwise.

Before we hand control of speech to Facebook or to Congress to free us from the complications of the Unreal, we would benefit from mapping this space more comprehensively. The goal of this issue of the Journal of Design and Science is not to conclusively define the Unreal, but to explore some of its dimensions. The nature of the beast is such that a singular view of the Unreal would always be incomplete, so we should expect these visions to challenge and conflict with one another as much as they mutually reinforce.

Given antecedents in agnotology within the Russian media space, we invited Peter Pomerantsev, a celebrated writer on contemporary Russia, to explore the idea of unreality as a mirror of a society facing a post-ideological world. Pomerantsev argues that understanding the purpose of disinformation is like trying to understand the purpose of art. Propaganda, like art, simply exists. It's just a reflection of the time.

Masha Gessen, professor at Amherst College, author of The Man Without a Face: The Unlikely Rise of Vladimir Putin, and contributor to The New Yorker, has challenged overly simplistic narratives of Putin as a singular architect of Russian media interventions. In conversation, she and I explore the idea that the unreal can still be corrosive to democracy even if there's no grand plan behind the complex and conflicting forces that lead to Russian strategies in the information space.

Dr. Gregory Asmolov, a scholar of the Russian internet and early career fellow at King's College London's Russia Institute, argues that the participatory affordances of digital networks offer novel opportunities for political manipulation. Relying on his research on the use of social networks in Russia and Ukraine, he explores the idea that manipulations of social media seek to divide friends, breaking alliances and leaving individuals isolated, online and offline.

Dr. Joan Donovan, Director of the Technology and Social Change Research Project at Harvard's Shorenstein Center on Media, Politics and Public Policy, is one of the nation's leading scholars on online disinformation. As someone who has watched the St. Petersburg-based Internet Research Bureau very closely, her essay with colleague Brian Friedberg, examines the power of pseudonymous identities that adopt the persona of oppressed people to capture their voices and power.

Julia Ebner, an Austrian scholar and researcher at the Institute for Strategic Dialogue, whose book The Rage is a leading resource on Islamist and far-right extremists in Europe, uses her knowledge of NeoNazi organizing online to give us a tour of alternative infrastructure to support speech that quotidian platforms have rejected. 
Unreality can also be routine, as Nina Lutz, an MIT Media Lab researcher on computational geometry and computer graphics explores in an essay that examines how makeup can be used to completely transform identity, and how these transformations impact our understanding of real and fake.

Dr. Judith Donath, former MIT Media Lab professor and alumna, researcher at the Harvard Berkman Klein Center for Internet and Society, author of The Social Machine, expands on her current research on signalling theory to explore the idea of the "deep fake" and to examine our relationship with video as an arbiter of truth, arguing that we must move from understanding video as reality to video as testimony.

Pursuing other spaces where the Unreal pokes into our everyday life, entrepreneur, game designer and former MIT Media Lab professor Kevin Slavin looks at how alternative reality games, a space first explored in the late 1990s and early 2000s, may have prefigured some of the fractures in reality we are encountering today.

And finally, Benjamen Walker, whose Theory of Everything podcast has long been one of the most prescient and provocative explorations of internet culture, reflects on a recently completed series, "False Alarm," that explored the blurry lines between fact and fiction. What happens to a media maker whose practice skates across reality's boundaries when the shifting of those boundaries becomes a moment of crisis for society at large?

We will be releasing these essays - and hopefully others - in pairs over the summer of 2019 and encouraging readers to react to them online, inviting other scholars in the field to comment specifically, but also taking advantage of this digital platform's affordances to solicit reactions both to our work and to other voices who should be included in the project.

Keeping firmly in mind the idea that progress is possible through this sort of plurality, I want to return to the question that frequently circulates in the QAnon community: Who is $\mathrm{Q}$ ?

Is $Q$ a dissident intelligent agent in the President's inner circle? A team of agents? Or perhaps President Trump himself? Is he (or she or they) a profit-making operation put together by opportunistic 4Chan trolls? A giant prank that has grown wildly out of control? A real-life role play, or LARP, as some QAnons like to describe it? Is $Q$ a Psyops effort, designed to keep up the spirit of Trump's most ardent supporters as the President struggles to drain the swamp as he promised them he would do? Is $Q$ an international disinformation operation designed to further pull apart the left and the right much as the Internet Research Agency sought to pull apart Black Lives Matter or the LGBTQ community?

The answer: $\mathrm{Q}$ is all of this and more. All of this for the simple reason that somewhere, someone believes this interpretation of $\mathrm{Q}$, and is working to impose that reality on the rest of us. This war 
between realities is the landscape we find ourselves collectively navigating. It is our task to understand how we act as individuals and citizens in a world where the emergent mode of discourse is not to persuade someone of your interpretation of the facts, but to recruit them to your own reality. Our ultimate challenge is not only to navigate this space but, at best, to heal and transform it. 